\title{
WIENER'S LIFE
}

\section{N. LEVINSON}

Wiener would have been extremely gratified had he known that the American Mathematical Society would honor him in death with an issue of the Bulletin. He had had a failing heart for many years and death had come to hold no fear for him, but the possibility of lack of esteem by his colleagues was most painful to him. Unfortunately Wiener did have grave doubts all of his professional life as to whether his colleagues, especially in the United States, valued his work, and, unwarranted as these doubts were, they were very real and disturbing to him.

Wiener wrote a two-volume autobiography entitled Ex-prodigy and $I$ am a mathematician thereby giving posterity an unusually detailed and personal picture of himself, his family, his colleagues, his times and of how he became a mathematician. It is of course an entirely honest but also entirely subjective account. Some of us come off too well, but in my opinion others are treated with a harshness that was not always warranted. Thus this article will not agree completely with Wiener's own account of the same people and events.

Norbert Wiener was born in Columbia, Missouri, November 26, 1894. His father, Leo Wiener, was a most remarkable man who had a tremendous influence on Norbert. Leo Wiener was born in Byelostok, in the ghetto area of Tsarist Russia, in 1862. He was a descendant of Aquiba Eger, Grand Rabbi of Posen from 1815 to 1837 . He was also supposedly descended from Moses Maimonides. Leo Wiener's father had already broken with the ancient narrow Yiddish tradition of the ghetto and Leo was raised with literary German rather than Yiddish as his language. Whatever mixed feelings Norbert Wiener may have had as an adolescent on first realizing he was a Jew were completely gone when I met him in 1933 . He was extremely proud of his scholarly ancestors and of the outstanding achievement of the Jews in mathematics, the physical and biological sciences and medicine. An account of his Jewish origin begins on the second page of Ex-prodigy [165]* and continues for a number of pages. He had an interesting theory to account for Jewish devotion to learning. It was in fact the case that a young man who was a good Talmudic scholar, no matter how poverty stricken or unworldly, was considered a good match for the daughter of even the wealthiest family.

* The bold-faced numbers in brackets refer to the numbered references in the Bibliography of Norbert Wiener. 
Adhering to Orthodox tradition the couple would raise a large family supported by the wife's father or by the wife herself. At the same time over the centuries the learned Christian young man entered the Church and was barred from marriage. This process repeated over tens of generations could have added a genetic bias to the existing cultural bias for learning that prevailed among the Jews.

Leo Wiener was a very intelligent and independent young man. Supporting himself from the age of thirteen onward, he graduated from a Warsaw gymnasium, which was an uncommon achievement for a Russian Jew faced as he was with the anti-Semitic laws of Tsarist Russia and with the insularism of Orthodoxy. There followed an abortive period as a medical student at Warsaw and then an abortive attempt as a technical student at Berlin. All this was over by the time he was eighteen when he emigrated to the United States alone and penniless. He never did get a university education. In the United States he was a factory worker, farmer, peddler, country school teacher, high school teacher, and then a foreign language teacher at the University of Missouri. Always extending his knowledge by intensive reading he eventually became a professor of Slavic languages at Harvard and a philologist of importance.

Norbert's mother, Bertha Kahn Wiener, was born in Missouri. She had one non-Jewish grandparent. However, her family was in the process of being assimilated, all of her mother's brothers having married non-Jews.

Soon after Norbert's birth the family moved to Boston and with his uncommon energy and obvious ability Leo Wiener quickly obtained a position at Harvard. Norbert was a timid anxious child who was sustained by the "solicitude and tenderness," to use his words, of his mother. Bertha Wiener tried to compensate socially for her unconventional husband. Norbert described him as "brilliant," "absentminded" and "hot tempered." (How well these adjectives applied also to Norbert himself.) Even if this extremely intense man had been a Mayflower descendant, his personality would have made him a maverick at Harvard. Actually, to further aggravate matters, he was an Eastern European Jewish immigrant with no university degree. His unconventionality certainly made his life more difficult. Later when Norbert displayed a similar markedly unconventional personality, his mother tried to smooth over some of the rough spots but to no avail. Had she prevailed, his earlier years would have been much less difficult.

In the summer of 1901 the family travelled to Europe. Norbert particularly remembers visiting Israel Zangwill, the writer and Zion- 
ist, and Prince Kropotkin, the Russian nobleman turned Anarchist. (Some thirty years later a student of Wiener's turned out to be the natural son of Kropotkin's secretary.)

Norbert learned to read spontaneously at a very early age and also picked up arithmetic. Already by six he was reading the widest variety of books in his father's library. He was attracted to zoology, physics and chemistry. One article he read as a child excited in him "the desire to devise quasi-living automata" $[165$, p. 65$]$. Cybernetics had an early birth!

At seven an attempt was made to enroll him in public school. However he did not fit readily into any grade and his father took him out of school and became his teacher. Anyone who has taught a wife or child, even something as simple as driving a car, knows the tensions that arise in such a family situation. No wonder then that the overly sensitive boy came to regard his perfectionist and highly reactive father an "avenger of the blood" [165, p. 67]. His mother tried to defend him but in his eyes at least was not very successful.

While Norbert realized his father's unusual qualities, nevertheless even forty years later when he became depressed and would reminisce about this period, his eyes would fill with tears as he described his feelings of humiliation as he recited his lessons before his exacting father. Fortunately he also saw his father as a very lovable man and he was aware of how much like his father he himself was.

With his father he went through the mathematics textbooks of Wentworth up to and including analytic geometry. He also learned Latin and German. On his own he read biology texts and a vast amount of literature. The science fiction of H. G. Wells and Jules Verne delighted him. During this period he had many neighborhood playmates and also enjoyed contact with his grandmothers, aunts, uncles and cousins.

When Norbert was nine the family moved to Harvard, Massachusetts and he was enrolled in nearby Ayer High School, which he completed at age eleven. The small town high school was a friendly place for this unusual child and he retained a warm affection for his friends in Ayer.

In 1906, aged eleven, Wiener entered Tufts College. Very wisely his father had decided not to subject the nervous boy to the tension of the Harvard entrance examinations and the publicity that would be given an eleven year old at Harvard. In order to make it unnecessary for Norbert to commute, the family moved to Medford Hillside. His major subject was mathematics but, except for a special reading course in Theory of Equations in his freshman year, the mathematics 
courses did not go far and the material covered was that suited to train engineering students of that period. The course in Theory of Equations included some Galois theory and was "over my head" $[165$, p. 104] as Norbert put it.

From his own account of his Tufts education it is clear that physics and chemistry impressed him much more profoundly than his mathematics courses. As we shall see, he was not in fact a prodigy in mathematics. With a neighborhood friend he carried out experiments in electrical engineering. They attempted to execute two of his ideas. Both ideas were excellent and show he was indeed a prodigy in engineering if not in mathematics. His first idea was to design an electromagnetic coherer for wireless messages. It depended on the fact that a magnetic field would compress a mass consisting of iron filings mixed with powdered carbon and thereby decrease the resistance of the mass. The invention of the vacuum tube made this device unnecessary. His second idea was to build an electrostatic transformer by charging a sequence of rotating glass disks through electrodes arranged in parallel and discharging them in series. Years later there was such an apparatus in operation.

He studied some philosophy and read much more of it than was required. Through his father he met William James. In his last year at Tufts his main interest was biology and consequently he was enrolled in 1909, not quite fifteen years old, in the Harvard Graduate School to work in zoology.

He had not been elected to Phi Beta Kappa at Tufts and this hurt him so much that he was opposed to honor societies for the rest of his life. He felt rebuffed and unwanted by the adult community, which he believed was suspicious that prodigies were doomed to failure. At this time he also became acutely aware of the transient character of life and obsessed by fear of death. "Like many other adolescents, I walked in a dark tunnel of which I could not see the issue, nor did I know whether there was any. I did not emerge from this tunnel until I was nearly nineteen years old and had begun my studies at Cambridge University (1913). My depression of the summer of 1909 did not suddenly end; rather it petered out" [165, p. 121].

Unfortunately for Norbert he was a failure at laboratory work which meant that he could not continue in biology. He lacked manipulative skill, good eyesight, and the patience required for meticulous work. It was a hard blow, since he wanted to be a biologist.

There were four other prodigies at Harvard at the time. Among these were A. A. Berle and the composer, Roger Sessions. Both of 
these men and Wiener had very successful careers. Of the other two, one died early of a ruptured appendix and the other never matured enough emotionally to function successfully.

Norbert's failure in biology led Leo Wiener to urge him to go into philosophy in which he had made a good record at Tufts. Norbert complied but in later years he came to resent what he regarded as an unwarranted interference on his father's part. Actually at the time it was an entirely reasonable proposal. (We shall see that somewhat later it was his father who proposed that he go into mathematics.) The academic year saw Norbert at the Sage School of Philosophy at Cornell. The year was not a success. Problems of adolescence, some inner turmoil about handling his Jewishness, marked social ineptitude and immaturity, and an apparent inability to function well outside of the sheltered family environment caused him to do an average rather than superb job with his courses. He blames vegetarianism, inculcated by his father, for some of his difficulties but this seems far fetched. A fellowship he had been given was not to be renewed. As a consequence his father arranged for his transfer to the philosophy department at Harvard, an action which he again came to resent as an unwarranted interference. On the other hand, with all of his difficulties, his father did regard him as a success.

One of his courses at Cornell had been in the theory of functions of a complex variable but he did not understand it. In part he attributes this to his own immaturity and in part to an overly intuitive approach on the part of the instructor. As to the latter, Osgood's excellent Lehrbuch had been published several years earlier and a little enterprise would have turned up this or some other adequate treatment. Hence we can only conclude that, in contrast to his early general intellectual development, in mathematics he was not to be an early bloomer.

The chapter of his autobiography on his Harvard years, 1911-1913, is entitled "A Philosopher Despite Himself." This seems to imply unhappiness or frustration. Actually the tone and content of the chapter indicate that these were two positive and successful years for Norbert. He does let slip at one point that with his sharp mind and keen wit he strove mightily and no doubt with considerable success to be "a thorn in the flesh of my mentors" [165, p. 167]. In so doing he could only have sharpened their awareness of his immaturity.

During this period he studied the border area between philosophy and mathematics with E. V. Huntington of the Harvard Mathematics Department. He refers to Huntington as "a magnificent teacher and a very kind man" [165, p. 167]. Huntington was an ex- 
pert on setting up systems of postulates which were not redundant and which had nontrivial realizations. Some of Wiener's early research was to be exactly along these lines.

His $\mathrm{Ph} . \mathrm{D}$. thesis was in mathematical logic. Owing to the illness of the Harvard philosopher Josiah Royce he worked with Professor Karl Schmidt of Tufts. Schmidt suggested for his topic a comparison between the algebra of relatives of Schroeder and that of Whitehead and Russell. Wiener found the work easy although later, under Russell, "I learned that I had missed almost every issue of true philosophical significance" $[165$, p. 171]. Subsequently he was to do good independent work in mathematical logic.

The prospect of his written and oral Ph.D. examinations terrified him. In looking back he felt his father helped him very much by distracting him with long walks and by drilling him with numerous questions. By his own standards he feels that he was so paralyzed with fear that he should have been failed in his orals. The examining professors, apparently sensing his fright and knowing his ability from his other work, passed him. He never forgot this experience and was always sympathetic to students showing signs of examination stress.

During his last year at Harvard he applied for and was awarded a travelling fellowship which he decided to use by studying with Bertrand Russell at Cambridge University. He was soon to be nineteen years old. In personality he was at extremes being on the one hand sharply aggressive and on the other immature, dependent and lacking in confidence. He had gone far in his studies but had not yet displayed the creative powers which would make him a great mathematician and then an outstanding philosopher of science.

During the summer of 1913 , prior to his departure, Huntington recommended that he read Bôcher's Modern algebra and Veblen and Young's Projective geometry. Strangely the first book, which was packed with material useful to a budding analyst, did not impress him at the time, although he returned to it many times later. He was still very much the logician and the postulational approach of Veblen and Young appealed to him very much.

The whole Wiener family was to spend the winter in Europe-but he was to be on his own in Cambridge. Russell, the logician and philosopher, was his chief mentor there. Norbert was now mature enough to be on his own and Cambridge was a pleasant social experience. Interestingly enough Russell had a decisive influence in preparing him for his still far away career as a mathematician. Russell suggested that a logician and philosopher of mathematics should take some mathematics courses. Accordingly he took courses with 
Hardy, Littlewood and Mercer. Hardy's lucid course covering the essentials of real variable theory including the Lebesgue integral and also an introduction to complex variable theory had a lasting influence on him which however was only to be revealed some six years later.

His main course work was with Russell. The immediate influence of this course on Wiener was profound but in the long run it was of no consequence compared to the effect of certain collateral reading recommendations Russell made to his students. Russell recognized the importance to the philosophy of science of Einstein's theory of relativity and suggested Einstein's three great papers of 1905 as reading material. One of these papers was on Brownian motion a subject in which, within ten years, Wiener was to have one of his greatest mathematical successes. Russell also saw the importance of electron theory and urged Wiener to study it, including the then new work of Nils Bohr. Russell obviously had a very keen sense for what was important in physics.

Many of the Cambridge dons were extreme individualists and markedly eccentric to the point where there was a certain competitiveness to excel in this direction. Wiener, who was presumably conducting himself as decorously as he possibly could, was inherently enough of a deviant so that some of his Cambridge friends thought he had carefully, deliberately and skillfully modified his behavior in order to excel in the competition and accordingly complimented him for his originality. He apparently was now sufficiently sophisticated not to disillusion them.

Wiener's first paper [1], which was on set theory, appeared at this time. His most noteworthy contribution to logic is described objectively by him "... in connection with the course [of Russell] I did one little piece of work which I later published; and although it excited neither any particular approval on the part of Russell nor any great interest at the time, the paper which I wrote [4] on the reduction of the theory of relations to the theory of classes has come to occupy a certain modest permanent position in mathematical logic" [165, p. 191]. In all, Wiener was to write some fifteen papers on logic and philosophy before shifting to analysis.

Because Russell was to be away from Cambridge for the May term it was decided that Norbert should finish the year at Göttingen. At Göttingen he again made a good adjustment but was not as strongly influenced by Hilbert, Landau or the philosopher Husserl, as he had been by Russell and Hardy. He appears to have undervalued Landau, who had also been a child prodigy.

Wiener took part in the social life at Göttingen and met many 
young mathematicians from Europe and the United States. One of these of whom Wiener was very fond was Otto Szasz who Wiener later helped come to the United States when Hitler came to power. Szasz with his gentle modesty, his clear and elegant lectures and his interest, as he put it, in small problems, (likening himself to an artist who painted miniatures), was the very opposite of Wiener.

Wiener submitted an essay [2] to compete for a Bowdoin Prize which Harvard awarded him. He did not regard his paper as having any great merit. During this period he had his first experience with the compulsive obsession and passion that is sometimes necessary for achieving success in research [6]. Of himself he says: "Granted an urge to create, one creates with what one has. With me, the particular assets that I have found useful are a memory of a rather wide scope and great permanence and a free-flowing, kaleidoscope-like train of imagination which more or less by itself gives me a consecutive view of the possibilities of a fairly complicated intellectual situation. The great strain on the memory in mathematical work is for me not so much the retention of a vast mass of fact in the literature as of the simultaneous aspects of the particular problem on which I have been working and of the conversion of my fleeting impressions into something permanent enough to have a place in memory. For I have found that if I have been able to cram all my past ideas of what the problem really involves into a single comprehensive impression, the problem is more than half solved. What remains to be done is very of ten the casting aside of those aspects of the group of ideas that are not germane to the solution of the problem. This rejection of the irrelevant and purification of the relevant I can do best at moments in which I have a minimum of outside impressions. Very often these moments seem to arise on waking up; but probably this really means that sometime during the night I have undergone the process of deconfusion which is necessary to establish my ideas. I am quite certain that at least a part of this process can take place during what one would ordinarily describe as sleep, and in the form of a dream. It is probably more usual for it to take place in the so-called hypnoidal state in which one is awaiting sleep, and it is closely associated with those hypnagogic images which have some of the sensory solidity of hallucinations but which, unlike hallucinations, may be manipulated more or less at the will of the subject" [165, pp. 212-213].

Cambridge and Göttingen mark the beginning of Wiener's emergence from child prodigy to young scientist. He was old enough to be regarded as a young adult and good enough to be accepted by his peers and elders as at least one of the rank and file of the coming 
intellectual generation. He was away from his father, an experience needed by most young people but especially important in his case.

Wiener returned to the United States at the beginning of World War I. Harvard again awarded him a travelling fellowship and he again went to Cambridge, which however soon almost ceased to function because of the War. He moved to London. "I looked up another Harvard fellow in philosophy, T. S. Eliot, who I believe, had taken Oxford to himself as I had taken Cambridge to myself. I found him in a Bloomsbury lodging, and we had a not too hilarious Christmas dinner together in one of the larger Lyons restaurants" [165, p. 220]. A short time later he returned to the United States planning to complete his fellowship at Columbia. He did not find the atmosphere there congenial and socially he regressed considerably. His sharp tongue and lack of social sensitivity made him something of a nuisance and accordingly he was treated badly by the graduate students in the dormitory in which he lived.

"My stay in New York also marked my introduction to the American Mathematical Society and my first visual acquaintance with most of the elder scholars of the group. At that time the hotel headquarters was that pile of Gay Nineties respectability, the old Murray Hill Hotel. The Society was then more of a New York institution than it is at the present time, for it had indeed been founded by a New York group, and had been known for some years as the New York Mathematical Society. There attached to it a little of a beerhall flavor, which has evaporated with time and the increased prosperity and respectability of the scientist" [165, p. 224].

Toward the end of the academic year he was hurriedly summoned home. A former fellow student, who had become an instructor in philosophy, informed the philosophy department that several years earlier Wiener had bribed a janitor to obtain for him some of his actual grades in an examination where the only result legitimately available to the student was whether he had passed or failed. Such an incident had occurred but without any bribery. It did not involve cheating in an examination but was nevertheless unpleasant. Wiener's future career was then being considered by the philosophy department and this charge may well have contributed to his later inability to obtain a position in philosophy. The Harvard philosophy department had earlier promised him the position of assistant and on this they did not renege.

Wiener had joined the Appalachian Mountain Club in 1912 and remained a member for the rest of his life. He was a devoted walker and rock climber. In the summer of 1915, after Columbia, he went 
on a long trip through the White Mountains with some former classmates. Then he returned to Harvard to his duties as assistant in philosophy. These included lecturing in elementary philosophy to a section at Harvard and to one at Radcliffe. He also chose to offer a free series of Docent Lectures.

Judging from his own remarks and from his later weakness as an undergraduate teacher his elementary teaching was probably at best passable. In the Docent Lectures "it was my intention to supplement postulational methods by a process according to which the entities of mathematics should be constructions of higher logical type, formed in such a manner that they should automatically have certain desired logical and structural properties" [165, p. 230]. Unfortunately there were some gaps in the reasoning which Wiener had not foreseen but which were picked up by Professor G. D. Birkhoff of the Harvard mathematics department who was attending the lectures. Had these lectures been a success it is plausible that his future in philosophy would have been secure.

Wiener enrolled in Birkhoff's course on the three body problem but could not follow it and discontinued attendance. He was now twenty one. Men of about that age who were never to attain anything like Wiener's ultimate success did follow Birkhoff's courses and indeed in some cases were inspired to the peak research of their careers while still his students. Wiener's coming of age as an analyst apparently could not be hurried. Wiener did become a regular attendant of the Harvard Mathematical Society. There he saw Osgood, Bôcher, G. D. Birkhoff, Huntington and Coolidge. His deep seated insecurity caused him to believe that the Harvard mathematics professors were looking down at the students including himself.

Wiener was living with his family. His parents gave Sunday teas for his father's and his own students. These teas gave him much needed experience in handling himself socially and in making friends. It was at one of these teas that he was later to meet his future wife.

Despite his contact with mathematicians and mathematics, Wiener's research work continued to be mainly in logic, then unfortunately something of a stepchild of both philosophy and mathematics. His work was not regarded as really outstanding even by himself and his productivity fell sharply once he started his assistantship. He was hoping to join a philosophy department but apparently he was not being highly recommended. Given all the facts as they have already been recounted in some of the last half dozen paragraphs, it is not clear how he could have been given high recommendations. 
At this point Leo Wiener pressed him to look for a job in mathematics instead of philosophy by registering with teachers' agencies. Thus, nearly twenty two, Wiener turned to a career in mathematics on advice from his father and not spontaneously. We can only guess what his future might have been had some department of philosophy seen fit to hire him in 1916. As it was an instructorship in mathematics turned up at the University of Maine.

The war continued but did not yet involve the United States. During the summer Wiener went to Plattsburg to train for a commission as a reserve officer. Although he was with a group training to become officers and therefore unquestionably somewhat select, he was shocked by their drinking and swearing. Once his tentmates realized how sensitive he was, they taunted him mercilessly. Needless to say he was not judged to be officer material on finishing camp.

The year at the University of Maine was a nightmare. He was inexperienced and almost certainly inept in presenting the elementary courses assigned him. He was younger than his years, over reactive, nervous and an easy victim to baiting. The students made his life miserable. He did manage to meet a few research-minded people led by Raymond Pearl, later a statistician at Johns Hopkins Medical School. "When the war finally came, I asked to be released from my teaching responsibilities to enter some branch of the service, for I was no less eager to leave Maine than the University was to see the last of me" [165, p. 243].

He made some tries at enlisting but his bad eyesight brought rejection. He joined an Officer's Training Corps at Harvard but also to no avail. He spent the rest of the summer reading algebraic number theory and trying his hand at the four-color problem, Fermat's last theorem and the Riemann hypothesis, although his mathematical knowledge at the time was extremely limited. In any case he was apparently becoming more committed to mathematics.

In the fall he obtained a job as an apprentice engineer in the turbine department of the General Electric Co. at Lynn. This was followed by a job for Encyclopedia Americana in Albany, at which he was happy. With the approach of the summer of 1918 he decided to look for a mathematics teaching job again. At that point he was asked to join the ballistic staff at the Aberdeen Proving Ground headed by Professor Oswald Veblen who had been made a major.

At Aberdeen he found Veblen, Bliss, Gronwall, Alexander, Ritt, Bray, Franklin (later his brother-in-law), Gill, Poritzky, Widder, Graustein, and many more. Franklin and Gill, both some four or five years his junior, were his closest friends. About the Proving Ground he 
writes, "Curiously enough, it furnished a certain equivalent to that cloistered but enthusiastic intellectual life which I had previously experienced at the English Cambridge, but at no American university" [165, p. 258]. He finally managed to enlist as a private but remained assigned at Aberdeen.

With the end of the war came a terrible influenza epidemic. Among its many victims was G. M. Green, a promising young Harvard mathematician, and fiancé of Constance, Norbert's sister. Green's parents gave his mathematics books to Constance, herself a student of mathematics, and in this way Norbert had an opportunity to read them. The books included Osgood's "Funktionen theorie," Lebesgue's book on integration, and Fréchet's book on the theory of functionals, and several books on integral equations. Wiener says, "For the first time, I began to have a really good understanding of modern mathematics" [165, p. 265]. This is an astounding statement from the twenty-four year old Wiener. Five years earlier he had taken Hardy's course, which included the Lebesgue integral and some complex variables. Three years earlier he had been a faithful attendant at the Harvard Mathematical Society meetings. He had tried his hand at the hardest problems in mathematics but apparently had not browsed through the mathematics stacks at the Harvard library. At that time there were relatively few mathematics books and in a few hours one could make a superficial acquaintance with all of them. Had he done so he could easily have purchased such books as that of Osgood, who he of course knew very well personally, of Lebesgue, and of Fréchet. As it was, these books came into his hands purely by chance. One can only conclude that in mathematics, as distinct from logic, his attitude was still very much that of an amateur. Aside from the books of Green he also had access to a set of lecture notes on the Lebesgue integral which his sister Constance had taken at the University of Chicago.

He spent a few months as a reporter for the Boston Herald but did not do well. He then wrote two papers (probably [9] and [10]) on an "extension to ordinary algebra of Sheffer's idea of a set of postulates with a single fundamental operation" [165, p. 269]. Sheffer was at Harvard and had earlier told Wiener about his discovery. Wiener regarded these as "by far the best pieces of mathematical work that I had yet written" [165, p. 269]. However he was soon to leave logic and postulational theory for analysis, the kind of analysis he had learned from the books of Green.

In the spring of 1919, through the good offices of Professor Osgood, Wiener obtained a position for the coming academic year in the 
mathematics department of the Massachusetts Institute of Technology. At the time this was not a particularly distinguished department but a number of its younger faculty were active in research. The major duty of the department was teaching calculus to engineering students. If the department was not outstanding neither was Wiener at the time. He had never written a paper in what was then regarded as mathematics, he had only an undergraduate degree from Tufts in the subject, his teaching record was at best mediocre, and he was immature and eccentric. One wonders if Osgood would have acted had Leo Wiener not been his friend and colleague. Norbert certainly did not feel indebted to Osgood for finding him the position.

At M.I.T. Wiener's teaching load was more than twenty hours a week of elementary calculus. He was sufficiently energetic so he didn't find this a serious liability. The students were serious and he soon learned how to get along with them. He compensated for his tendency to lecture over their heads by grading liberally. His eccentricities were not regarded as out of place in a college teacher and indeed the students seemed pleased to have at least one teacher who could not be mistaken for anything except a budding college professor.

Since the other members of the mathematics department were not particularly distinguished, the insecure young Wiener did not get the feeling they were looking down at him or that he was under any pressure from them to achieve greatness. Actually M.I.T. was an ideal environment for Wiener at that time when the transition to analysis still lay ahead of him. He felt free to tell his colleagues about his ideas and, if he was unduly and prematurely optimistic about them, they nevertheless encouraged him and did not dampen his ardor. They also tried to buoy him up in his periods of self doubt and deep depression. While they didn't always understand him, they did sense the possibility that his brightness and enthusiasm could lead to real achievement.

In the summer before going to M.I.T. Wiener had a great stroke of good fortune. He received a visit from I. A. Barnett, then himself a young mathematician and a former student of E. H. Moore. Apparently influenced by the book of Fréchet which had been in Green's collection, Wiener aspired to work in functional analysis. He asked Barnett, as one trained in this area, to suggest a good research problem to him. "His reply has had a considerable influence on my later scientific career. He suggested the problem of integration in function space" [165, p. 274]. In fact this suggestion of Barnett completely influenced the whole course of Wiener's work and his greatest achievements all stemmed from this problem. It was a happy accident that 
Barnett suggested a problem that turned out to be approachable by the mathematics of the time and yet was sufficiently difficult so that a solution was a real achievement. It was also a problem which when solved was to lead Wiener to more, equally important and pregnant problems.

He worked on this problem for two years before finally solving it. In the course of solving it he studied the Daniell integral and found in the literature unsatisfactory attempts at solution of the problem. An article by G. I. Taylor in the Proceedings of the London Mathematical Society (1920) excited his interest. It was on turbulence. In spirit it was applied rather than pure mathematics. It was important to Wiener for several reasons. One was that he then tried turbulence as a model for his problem. Another reason was that Taylor introduced a type of correlation between a function and its derivative. This was later to suggest to Wiener his autocorrelation and cross correlation functions in generalized harmonic analysis.

The notion of using turbulence as a model for his problem did not work out because turbulence is too complicated. This set Wiener to looking for a simpler model and then he thought of Brownian motion which he had studied in one of Einstein's papers some seven years earlier at Russell's suggestion. The paper of Einstein studied the statistical behavior of particles performing Brownian motion. Wiener's idea was to study the path of a single particle, or rather the ensemble of such paths. Each path became a point in his function space. He was able to show that almost all paths were continuous but nondifferentiable. He could compute the average of a functional over the ensemble of paths. He could not have realized at the time the effect his work was to have on the field of probability in the decades ahead. Here is what M. Kac says in 1964: "During the past two decades mathematicians have pursued an even more productive investigation of the theory of 'stochastic processes': the probabilistic analysis of phenomena that vary continuously in time. Stochastic processes arise in physics, astronomy, economics, genetics, ecology, and many other fields of science. The simplest and most celebrated example of a stochastic process is the Brownian motion of a particle.

"The late Norbert Wiener conceived (in 1921) the idea of basing the theory of Brownian motion on a theory of measure in a set of all continuous paths. This idea proved enormously fruitful for probability theory. It breathed new life into old problems . . . . More than that, it opened up entire new areas of research and led to fascinating connections between probability theory and other branches of mathematics" (Sci. Amer. 211 (1964), No. 3, 105). 
All of this was to take some years in coming and neither Wiener nor anyone else were aware of the implication of his "Differential space." For Wiener even in the early nineteen twenties the Brownian paths were examples of phenomena which were like turbulence, noise, white light, etc. in that they were not strictly periodic and hence not describable by Fourier series nor were they transient in time and hence were not describable by a classical Fourier integral. $\mathrm{He}$ also had the suggestion of Taylor's special case of a correlation function in the study of turbulence. All this was soon to lead him to generalized harmonic analysis. Before this, however, he did several other pieces of work.

In 1920 Wiener had gone to an International Mathematics Congress at Strasbourg. He spent some time with Fréchet whose work he wished to extend. He found a satisfactory set of axioms for vector spaces. But a few weeks later an article by Banach appeared with exactly the same postulates. Wiener's results were published later than Banach's and he added an appropriate reference. Wiener did not stay in this field.

Wiener felt all of his life that Harvard had not treated him well. Actually, as we have seen, Harvard has provided him with two postdoctoral fellowships followed by a year as an assistant in philosophy. Osgood, of the Harvard Mathematics Department, had found the position in the M.I.T. Mathematics Department for him. After Wiener came to M.I.T., he apparently consulted frequently with Kellogg of Harvard about potential theory in which Kellogg was an expert. Kellogg quickly brought him to the research frontiers of this field and Wiener successfully solved some important problems on the behavior of an harmonic function at its boundary which unquestionably brought him more recognition at the time than his Brownian motion work. Unfortunately there arose a problem of timing his publications so as not to compromise the theses of two of Kellogg's students. Actually the matter resolved itself satisfactorily although this is not made clear in Wiener's account. Wiener unfortunately felt that Kellogg had been unfair to him. Thus instead of feeling indebted to Kellogg he again felt that Harvard was mistreating him.

Time has shown Wiener's Brownian motion paper to be more important than his very good work in potential theory. As already stated, Brownian motion is an example of a whole class of physical phenomena the study of which led Wiener to his generalized harmonic analysis. Wiener's own account of how he was led to generalized harmonic analysis is full of references to engineering particularly to communication theory. Most of Wiener's important work was in- 
spired by physics or engineering and in this sense he was very much an applied mathematician. On the other hand, he formulated his theories in the framework of rigorous mathematics and as a consequence his impact on engineering was very much delayed.

"For several years the chief demand made on me at M.I.T. by the electrical-engineering department was to put the Heaviside calculus on a proper logical foundation. Other people were doing the same thing at the same time in other countries although I do not think that any of these treatments were more satisfactory than the one which I ultimately gave. In performing this task, I had to study harmonic analysis on an extremely general basis, and I found out that Heaviside's work could be translated word for word into the language of this generalized harmonic analysis.

"In all this there was an interplay between what I was doing on the Heaviside theory and what I had done on the Brownian motion. Previous to my work there had been no thoroughly satisfactory example given of the sort of motion that would correspond to sound or light with a continuous spectrum - that is, with energy distributed continuously in frequency instead of being lumped in isolated spectrum lines. The harmonic analysis which had already been given corresponded more closely to what one sees when one examines the light of sodium vapor than what one sees when one examines sunlight. (The light of sodium vapor is concentrated in a number of bright lines, whereas sunlight has a continuous distribution in color and consequently in frequency.)" [177, p. 78].

"I found that it was possible to generate continuous spectra by means of the Brownian motion or the shot effect and that if a shoteffect generator were allowed to feed into a circuit that could vibrate, the output would be of that continuous character. In other words, I already began to detect a statistical element in the theory of the continuous spectrum and, through that, in communication theory. Now, ..., communication theory is thoroughly statistical, and this can be traced directly back to my work of that time" [177, p. 79].

From G. M. Green's copy of Fréchet's book Wiener was led to ask Barnett for a problem in functional analysis. Barnett's question led Wiener to set up "Differential space" modelled on Brownian motion (studied at the suggestion of Russell) and this in turn led him to generalized harmonic analysis. One of the problems that arose in generalized harmonic analysis led to Wiener's general Tauberian theorems. Such is the role of chance in great discoveries of science. To see how the latter events occur let us look briefly at generalized harmonic analysis. 
The class of functions Wiener considered in his harmonic analysis were those $\{f(t)\}$ which were measurable and for which

$$
\phi(x)=\lim _{T \rightarrow \infty} \frac{1}{2 T} \int_{-T}^{T} f(x+t) \bar{f}(t) d t
$$

exists for all $x$. In the special case

$$
f(t)=\sum_{1}^{N} a_{n} e^{i \lambda_{n} t}
$$

$\lambda_{n}$ real,

$$
\phi(x)=\sum_{1}^{N}\left|a_{n}\right|^{2} e^{i \lambda_{n} x}
$$

If

$$
S(u)=\frac{1}{2 \pi} \int_{-\infty}^{\infty} \phi(x) \frac{e^{-i u x}-1}{-i x} d x,
$$

then $S(u)$ is a monotone step function with jumps of $\left|a_{n}\right|^{2}$ where $u=\lambda_{n}$. Thus

$$
\phi(x)=\int_{-\infty}^{\infty} e^{i u x} d S(u)
$$

If $u_{1}$ and $u_{2}$ are not equal to any $\lambda_{n}$,

$$
S\left(u_{2}\right)-S\left(u_{1}\right)=\sum_{u_{1}<\lambda_{n}<u_{2}}\left|a_{n}\right|^{2}
$$

Thus $S\left(u_{2}\right)-S\left(u_{1}\right)$ is a measure of the energy of $f(t)$ between frequencies $u_{1}$ and $u_{2}$. If $f(t)$ is not a trigonometric polynomial, $S(u)$ is still monotone and the above formulas are valid.

From the existence of $\phi(0)$ follows readily that $|f(t)|^{2} /\left(1+t^{2}\right)$ is integrable $(-\infty, \infty)$ and hence in the sense of convergence in the mean there exists

$$
g(u)=\frac{1}{2 \pi} \int_{-1}^{1} f(t) \frac{e^{i u t}-1}{i t} d t+\frac{1}{2 \pi}\left(\int_{-\infty}^{-1}+\int_{1}^{\infty}\right) \frac{f(t)}{i t} e^{i u t} d t .
$$

Plancherel's theorem gives

$$
\frac{1}{2 \epsilon} \int_{-\infty}^{\infty}|g(u+\epsilon)-g(u-\epsilon)|^{2} d u=\frac{1}{\pi \epsilon} \int_{-\infty}^{\infty}|f(t)|^{2} \frac{\sin ^{2} \epsilon t}{t^{2}} d t .
$$


To obtain the interesting formula

$$
\lim _{\epsilon \rightarrow 0} \frac{1}{2 \epsilon} \int_{-\infty}^{\infty}|g(u+\epsilon)-g(u-\epsilon)|^{2} d u=\lim _{T \rightarrow \infty} \frac{1}{2 T} \int_{-T}^{\lambda}|f(l)|^{2} d l,
$$

it suffices to prove

$$
\lim _{\epsilon \rightarrow 0} \frac{1}{\pi \epsilon} \int_{-\infty}^{\infty}|f(t)|^{2} \frac{\sin ^{2} \epsilon t}{t^{2}} d t=\lim _{T \rightarrow \infty} \frac{1}{2 T} \int_{-T}^{T}|f(t)|^{2} d t
$$

in the sense that the existence of either side implies that of the other side. If one sets

$$
F(t)=|f(t)|^{2}+|f(-t)|^{2},
$$

the problem becomes

$$
\lim _{\epsilon \rightarrow 0} \frac{2}{\pi \epsilon} \int_{0}^{\infty} F(t) \frac{\sin ^{2} \epsilon t}{t^{2}} d t=\lim _{T \rightarrow \infty} \frac{1}{T} \int_{0}^{T} F(t) d t .
$$

Wiener attempted to prove $\left({ }^{*}\right)$. He was in Göttingen at the time, as was his friend A. E. Ingham. "It is to Ingham that I owe a scientific lead which has carried me to much of my best work" [177, p. 115]. The word "much" really should be replaced by "some." What Ingham told Wiener when he asked him about $\left({ }^{*}\right)$ was that it was a Tauberian theorem, in the terminology of Hardy and Littlewood, who had solved similar problems. To solve $\left(^{*}\right)$ Wiener, instead of trying to adapt the methods of Hardy and Littlewood, devised a highly original and powerful procedure in his general Tauberian theorems. A later lemma used to beautify this theory was his famous theorem on the reciprocal of a nonvanishing absolutely convergent Fourier series.

With $T=e^{x}, \epsilon=e^{-x}, t=e^{y}$ and $F\left(e^{y}\right)=H(y)$, Wiener noticed that (*) becomes

$$
\frac{2}{\pi} \lim _{x \rightarrow \infty} \int_{-\infty}^{\infty} e^{x-y} \sin ^{2}\left(e^{-(x-y)}\right) H(y) d y=\lim _{x \rightarrow \infty} \int_{-\infty}^{x} e^{-(x-y)} H(y) d y .
$$

Wiener had recast his problem to the following form: Let $K(x)$ be integrable and satisfy

$$
\int_{-\infty}^{\infty}|K(x)| d x<\infty, \quad \int_{-\infty}^{\infty} K(x) d x=1 .
$$

Let $K_{1}(x)$ satisfy the same conditions. Then under what conditions does the existence of 
(2)

$$
\lim _{x \rightarrow \infty} \int_{-\infty}^{\infty} K(x-y) f(y) d y=a
$$

imply that

$$
\lim _{x \rightarrow \infty} \int_{-\infty}^{\infty} K_{1}(x-y) f(y) d y=a ?
$$

In the simplest of Wiener's theorems one takes $|f(y)|$ as uniformly bounded. Let $R(x)$ satisfy (1) also. Then from (2) follows readily that

$$
\lim _{x \rightarrow \infty} \int_{-\infty}^{\infty} R(x-t) d t \int_{-\infty}^{\infty} K(t-y) f(y) d y=a
$$

so that if

$$
\int_{-\infty}^{\infty} R(x-t) K(t) d t=K_{2}(x)
$$

then

$$
\lim _{x \rightarrow \infty} \int_{-\infty}^{\infty} K_{2}(x-y) f(y) d y=a .
$$

If (5) holds for a class of $K_{2}(x)$ such as

$$
K_{2}(x)=\frac{\sin ^{2} N x}{\pi N x^{2}}, \quad 0<N<\infty,
$$

then from the convolution

$$
\int_{-\infty}^{\infty} K_{1}(x-t) d t \int_{-\infty}^{\infty} \frac{\sin ^{2} N(t-y)}{\pi N(t-y)^{2}} f(y) d y,
$$

one is led to (3). Thus Wiener reduced his problem to the solution of (4) for $R(x)$.

The equation (4) is a convolution. Defining

$$
k(u)=\int_{-\infty}^{\infty} K(t) e^{i u t} d t
$$

etc., one is led to replace (4) by

$$
r(u) k(u)=k_{2}(u)
$$

where 


$$
k_{2}(u)=\left(1-\frac{|u|}{N}\right), \quad|u| \leqq N=0, \quad|u|>N
$$

\section{Because}

$$
r(u)=\frac{k_{2}(u)}{k(u)},
$$

Wiener was led to his famous hypothesis

$$
k(u) \neq 0, \quad-\infty<u<\infty .
$$

Thus (7) implies

$$
\int_{-\infty}^{\infty}|r(u)|^{2} d u=\int_{-N}^{N}|r(u)|^{2} d u<\infty .
$$

In his early papers Wiener added a hypothesis of the type

$$
\int_{-\infty}^{\infty}|x K(x)| d x<\infty
$$

which led to the existence of $k^{\prime}(u)$ as a continuous function and hence from (7) to

$$
\int_{-\infty}^{\infty}\left|r^{\prime}(u)\right|^{2} d u<\infty
$$

From (8) and (10)

$$
\int_{-\infty}^{\infty}|R(x)|^{2} d x<\infty
$$

and

$$
\int_{-\infty}^{\infty}|x R(x)|^{2} d x<\infty
$$

where

$$
R(x)=\frac{1}{2 \pi} \int_{-N}^{N} r(u) e^{-i u x} d u .
$$

From (11) and (12)

$$
\left(\int_{-\infty}^{\infty}|R(x)| d x\right)^{2} \leqq \int_{-\infty}^{\infty}|R(x)|^{2}\left(1+x^{2}\right) d x \int_{-\infty}^{\infty} \frac{d x}{1+x^{2}}<\infty
$$


and so $R(x)$ satisfies (1) and the simplest of Wiener's Tauberian theorems is proved.

The condition (9) is satisfied in all cases of interest, but Wiener was unhappy with it and eventually (1931) replaced it by his famous theorem that if

where

$$
g(x)=\sum_{-\infty}^{\infty} a_{n} e^{i n x}
$$

$$
\sum_{-\infty}^{\infty}\left|a_{n}\right|<\infty
$$

and if $g(x) \neq 0$, then $1 / g(x)$ has an absolutely convergent Fourier series. This latter result was later recast by Gelfand in an abstract form which is probably much better known in contemporary mathematics than the actual Tauberian theorems of Wiener.

Wiener's first work in generalized harmonic analysis appeared early in 1926 and his Tauberian theorems in 1928. In 1924, Wiener had been promoted to an assistant professorship at M.I.T. But Wiener was not satisfied with his rate of promotion or with the fact that he was not invited to join one of the several departments with more prestige than that at M.I.T. In part he was merely paying the usual price, not a large one, for being an innovator. He was to receive ample recognition before long but he was extremely impatient. He resented what he thought was mistreatment by established mathematicians particularly those at Harvard. ". . . I knew very well that I was competitive beyond the run of younger mathematicians, and I knew equally that this was not a pretty attitude. However, it was not an attitude which I was free to assume or to reject. I was quite aware that I was an out among ins and that I would get no shred of recognition that I did not force. If I was not to be welcomed, well then, let me be too dangerous to be ignored" [177, p. 87]. This was hardly an attitude conductive to winning good will. Fortunately it is an exaggerated and lopsided account. Actually he could also be generous and jovial even though he was plagued by something of a persecution complex.

Because of their own mathematical interests J. D. Tamarkin of Brown, an émigré from the Soviet Union, and G. H. Hardy were among the first to appreciate Wiener's generalized harmonic analysis and Tauberian theorems and they helped establish his reputation. "He [Hardy] also thought well of my work, and between him and 
Tamarkin I began to be heard of in this country, but I was never able to forget that the people to whom I owed the greatest part of my recognition were not Americans" [177, p. 130]. In fact, with much less delay than often occurs in science, Wiener was to be accorded ample recognition from the American mathematical community.

In 1926 Wiener married Margaret Engemann, a young woman of considerable character and ability, who had emigrated with her widowed mother and brothers from Germany at age fourteen. His parents apparently seeing in her the maturity Norbert required in a mate, and probably anxious to get their aging fledgling out of the nest, strongly approved of the match. As Norbert's wife she would require tact, forbearance, and a willingness to assume almost all family responsibility, to shelter Norbert from outside distractions, to humor him when depressed, to allay his fears and anxiety, and to tolerate him in his unbounded flights of fancy when he was cheerful. She could not have known the job she was undertaking but she proved equal to it. She gave him as much peace of mind as was humanly possible so that he could pursue his work.

Norbert had become attached to the town of Sandwich in New Hampshire. His parents helped the young couple buy a home there to which they were to go for their vacations from then on. The house was set in a valley with the Ossipee Mountains to the south and Chocorua towering in the north. Kline, Wintner and other mathematicians were to come there regularly as a result of visiting the Wieners.

In 1929 Wiener was promoted to an associate professorship at M.I.T. His long paper on generalized harmonic analysis appeared in Acta Mathematica in 1930. Since he was not a good expositor Tamarkin helped with the preparation of this paper. There followed an equally important memoir on Tauberian theorems that appeared in the Annals of Mathematics early in 1932. With the appearance of these two important papers he was promoted to a professorship in 1932.

The year 1931-1932 was spent by the Wieners and their two small daughters, Barbara and Peggy in Cambridge, England. Here, on Hardy's invitation, Wiener gave a series of lectures which he then prepared as a book, The Fourier integral [81], published by the Cambridge University Press. Aside from presenting his work on absolutely convergent series, Tauberian theorems and generalized harmonic analysis, Wiener gave a very interesting proof of the Plancherel theorem based on his observation that the Fourier transform can be regarded as an operator having as its eigenfunctions the Her- 
mite orthogonal functions with eigenvalues that are $1, i,-1$, or $-i$.

Before he had left for Cambridge, Wiener had collaborated with E. Hopf on the solution of the integral equation

$$
f(x)=\int_{0}^{\infty} K(x-y) f(y) d y
$$

for $f(x)$. This equation occurs commonly in many applications and has come to be known as the Wiener-Hopf equation. In its solution a study of the Fourier transform in the complex plane is necessary. The Fourier transform as a function of a complex variable proved to be very important in Wiener's subsequent research.

In the year 1932-1933, back at M.I.T., Wiener had the young British mathematician R. E. A. C. Paley as a visitor. They collaborated on a number of theorems involving the Fourier transform in the complex plane. The result of their collaboration was the book Fourier transforms in the complex domain [92], an American Mathematical Society Colloquium Publication, 1934. Paley was killed in a skiing accident almost a year before the book was completed and most of the actual writing of the book was done by Wiener. Wiener was extremely generous in matters relating to collaboration and with no hesitation he listed Paley as a coauthor of the book. The most widely known theorems in the book have turned out to be those appearing in the introduction. One of these reads as follows: Let $F(s)$ be analytic for $-\lambda \leqq \sigma \leqq \mu, s=\sigma+i t$, and let

$$
\int_{-\infty}^{\infty}|F(\sigma+i t)|^{2} d t \leqq \text { const, } \quad-\lambda \leqq \sigma \leqq \mu .
$$

Then there exists a measurable $f(x)$ such that

$$
\begin{aligned}
& \int_{-\infty}^{\infty}|f(x)|{ }^{2} e^{2 \mu x} d x<\infty, \\
& \int_{-\infty}^{\infty}|f(x)|^{2} e^{-2 \lambda x} d x<\infty,
\end{aligned}
$$

and, for $-\lambda \leqq \sigma \leqq \mu$,

$$
F(\sigma+i l)=\lim _{A \rightarrow \infty}(2 \pi)^{-1 / 2} \int_{-A}^{A} f(x) e^{x(\sigma+i t)} d x .
$$

(Actually it suffices for $-\lambda<\sigma<\mu$ and the case $\lambda=0, \mu=\infty$ is so formulated by them.) 
It is interesting that Wiener who, as an innovator resented very much the more rapid recognition accorded the young scientist working in already accepted areas, should on achieving success himself, so strongly approve of those doing work in established areas close to his own as was the case with Paley and myself. Actually it seems inevitable that this be so and hence that the innovator has to expect the possibility of some delay in being recognized.

In 1933 Wiener was honored by the American Mathematical Society with the award of the Bôcher prize which he shared with Marston Morse. The prize is awarded every five years, and since Wiener's memoirs on generalized harmonic analysis and Tauberian theorems had appeared in 1930 and 1932 respectively, it is evident that the Society accorded him its highest honor as soon as it was possible to do so. At about the same time he was elected to the National Academy of Sciences. He stated that the crass bargaining for votes that preceded the annual elections of new members disgusted him and he quickly resigned.

In the summer of 1934 the American Mathematical Society again honored Wiener by inviting him to present the Colloquium Lectures. He presented material from his book with Paley at a pleasant meeting in Williamstown, Massachusetts. A little later he was elected a Vice President of the American Mathematical Society. His dislike for administrative duties precluded his holding the Presidency. In 1949 Wiener was invited to give the Willard Gibbs Lecture at the Annual Meeting of the Society.

Wiener had made frequent trips to Europe through 1927. In fact in 1926-1927 he had been a Guggenheim Fellow in Europe. As already stated 1931-1932 was spent in Cambridge, England. In 19351936 he was a visiting professor in China. In 1947, 1949, and 1951 he spent the fall terms in Mexico at the National Institute of Cardiology. In 1951 he was also a Fulbright Lecturer in Paris. In 1955-1956 he was a visiting professor in Calcutta, India. In 1960 and 1962 he spent a term at the University of Naples and in 1964 at the time of his death occupied a visiting position in Holland.

Wiener had an international outlook. Not only did he feel at home in Western Europe but also in Mexico, China and India. While he had visited the Soviet Union only briefly, he had long admired their achievement in mathematics.

I became acquainted with Wiener in September 1933, while still a student of electrical engineering, when I enrolled in his graduate course. It was at that time really a seminar course. At that level he was a most stimulating teacher. He would actually carry on his re- 
search at the blackboard. As soon as I displayed a slight comprehension of what he was doing, he handed me the manuscript of PaleyWiener for revision. I found a gap in a proof and proved a lemma to set it right. Wiener thereupon sat down at his typewriter, typed my lemma, affixed my name and sent it off to a journal. A prominent professor does not often act as secretary for a young student. He convinced me to change my course from electrical engineering to mathematics. He then went to visit my parents, unschooled immigrant working people living in a run-down ghetto community, to assure them about my future in mathematics. He came to see them a number of times during the next five years to reassure them until he finally found a permanent position for me. (In those depression years positions were very scarce.) If this picture of extreme kindness and generosity seems at odds with Wiener's behavior on other occasions, it is because Wiener was capable of childlike egocentric immaturity on the one hand and extreme idealism and generosity on the other. Similarly his mood could shift quickly from a state of euphoria to the depths of dark despair.

For several years after the publication of the Paley-Wiener book Wiener's mathematical work consisted mainly of extensions of his earlier theorems and methods. Much of this work was very good but was probably not his very best. In his paper, The homogeneous chaos, (1938) [108], an important added ingredient is the ergodic theorem. The addition of the ergodic theorem to his earlier techniques is probably the main feature that distinguishes Wiener's later mathematical work from that done in 1921-1934. On the advice of Hopf and Jessen, Wiener had already used the ergodic theorem in the last chapter of the Paley-Wiener book [92] but his really deep interest in it developed later.

During this period Wiener made the acquaintance of a Mexican physiologist Arturo Rosenblueth, at that time a collaborator of Walter Cannon at the Harvard Medical School. There began a collaboration which continued in Mexico after the War when Wiener spent several terms as a visitor of the National Institute of Cardiology. This collaboration certainly played a part in the development by Wiener of cybernetics.

Wiener felt uneasy about his mathematical work during the years immediately preceding World War II and pressed his colleagues to affirm that his productivity was not declining. He had always needed approval from those around him. His usual words of greeting became, "Tell me, am I slipping?" Whether one knew what he had been doing or not the only response anyone ever made was a strong denial. How- 
ever this was usually not enough and it was necessary to affirm in the strongest terms the great excellence of whatever piece of his research he himself would proceed to describe sometimes in the most glowing terms. Altogether such an encounter was an exhausting experience. Indeed at the time there was an instructor at M.I.T. slightly younger than myself who would complain bitterly about the expense of a chance meeting with Wiener. The man, now a very successful mathematician and known for his exuberance and bounce, found that the degree of enthusiasm he had to feign to meet the demands of Wiener left him enervated and without confidence in his own work. Such was his state that he would rush off to a psychiatrist. The fee of five dollars (25 years ago) was much more than he could afford. Whether this played a role in his early departure from M.I.T. he never said.

In the years preceding the War, Wiener became a supporter of the Spanish Loyalists. As a recent visitor to China he was also moved to be active in the political support of the Chinese in their struggle against the Japanese invasion of their country. Several of his younger friends and colleagues had become Communists-indeed Stalinists. Wiener saw in Stalinism a dogmatic new religion with naively simple formulas for curing the ailments that afflict humanity and he rejected it. Instead he reacted as an idealist and humanitarian to the rising turmoil of a world speeding toward disaster. He succeeded in helping a few colleagues, some Jewish and some Socialists, flee from Hitler Germany to the United States. It was during this period that he had his first experiences on the public lecture platform and he was good at it.

When the War finally came to Europe the United States began to mobilize its scientists. Wiener obtained a small grant to work on firecontrol. The problem was to design apparatus that would direct antiaircraft guns effectively. With the increase in speed of planes this was a difficult problem. It was necessary to determine the position and direction of flight of the aeroplane and then extrapolate over the flight time of the projectile to determine where the plane would be so that the projectile could be aimed so as to reach it. This problem stimulated Wiener to produce his prediction theory and also eventually brought him to cybernetics.

The mathematical problem of prediction as he formulated it was solvable by a synthesis of his own previous work. He could have handled it readily any time after 1931, had he conceived of the problem. As one well versed in the theory of linear electrical circuits and of the mathematical tractability of least squares procedures, 
Wiener formulated his problem more or less as follows: Consider a function of time $f(t)$ which is the sum of a function $g(t)$, (which could be a coordinate of the moving aeroplane) and a noise $f(t)-g(t)$. How best determine $g(t+h)$ for some $h>0$ from a knowledge of $f(t-\tau)$ for $\tau \leqq 0$ ? Method of solution: Choose $K(\tau), \tau \geqq 0$, so that

$$
\lim _{T \rightarrow \infty} \frac{1}{2 T} \int_{-T}^{T}\left[g(t+h)-\int_{0}^{\infty} K(t-\tau) f(\tau) d \tau\right]^{2} d t
$$

is minimized.

Proceeding informally the standard variational technique leads to an integral equation of the first kind for $K$ :

$$
\int_{0}^{\infty} \phi(t-\tau) K(\tau) d \tau=\chi(t+h), \quad t \geqq 0 .
$$

Here $\phi$ is Wiener's autocorrelation function for $f$,

$$
\phi(t)=\lim _{T \rightarrow \infty} \frac{1}{2 T} \int_{-T}^{T} f(t+\tau) f(\tau) d \tau,
$$

and

$$
\chi(t)=\lim _{T \rightarrow \infty} \frac{1}{2 T} \int_{-T}^{T} g(t+\tau) f(\tau) d \tau,
$$

Wiener's cross correlation function for $g$ and $f$.

The equation (13) is somewhat reminiscent of the Wiener-Hopf equation. It can be treated by the techniques available from the theory of Fourier transform in the complex domain. Actually Wiener's treatment of it was not the simplest possible. Also as in previous cases where Wiener started from a physical problem, his exposition was not directed to the engineer but rather to the pure mathematician. In earlier cases this had delayed the practical utilization of his discoveries, but there were trained mathematicians in the war laboratories who were able to adapt his ideas to the needs of applications. In some cases the modifications of his ideas for practical applications so trivialized the mathematics as to actually cause him pain. On the other hand he was gratified that his work was being used even where in one case as finally simplified, it boiled down to a slightly modified form of Gauss' least squares procedure and led to nothing more sophisticated mathematically than a system of $n$ linear algebraic equations in $n$ unknowns.

Wiener's prediction theory did have an important influence in 
engineering. His introduction of the statistical element in the question of the existence and significance of the auto- and cross-correlation functions proved very important, and his generalized harmonic analysis finally became a tool of applied mathematics. From the strictly mathematical point of view this appears to be the main contribution of Wiener to cybernetics which we will now consider.

In fire control as first examined in 1940-1941 by Wiener, the role of the human operator, who turned his cranks so as to keep a moving target on the cross hairs of his telescope, brought human neurophysiology into this problem. Wiener began to consider the reactions of the human being in terms of the theories of the communications engineer and found that feedback and stability which were of great importance in control problems in engineering were equally important in neurophysiology. We recall that Wiener had wanted very much to be a biologist but had failed in his first year of graduate school because he lacked the ability to do satisfactory laboratory work. Some thirty five years later he was able to make his mark in biology by way of his theory of control and communication as applied to man and machine in the theory he called cybernetics.

A part of the scientific material that enters into Wiener's cybernetics is from the work of others. His role in cybernetics was not only that of an innovator but also that of a publicist, synthesizer, unifier, popularizer, prophet and philosopher. He has been called the philosophizer of the age of automation. In cybernetics he returned to the field of philosophy he had left some twenty five years earlier.

"The whole background of my ideas on cybernetics lies in the record of my earlier work. Because I was interested in the theory of communication, I was forced to consider the theory of information and, above all, that partial information which our knowledge of one part of a system gives us of the rest of it. Because I had studied harmonic analysis and had been aware that the problem of continuous spectra drives us back on the consideration of functions and curves too irregular to belong to the classical repertory of analysis, I formed a new respect for the irregular and a new concept of the essential irregularity of the universe. Because I had worked in the closest possible way with physicists and engineers, I knew that our data can never be precise. Because I had some contact with the complicated mechanism of the nervous system, I knew that the world about us is accessible only through a nervous system, and that our information concerning it is confined to what limited information the nervous system can transmit.

"It is no coincidence that my first childish essay into philosophy, 
written when I was in high school and not yet eleven years old, was called The theory of ignorance. Even at that time I was struck with the impossibility of originating a perfectly tight theory with the aid of so loose a mechanism as the human mind. And when I studied with Bertrand Russell, I could not bring myself to believe in the existence of a closed set of postulates for all logic, leaving no room for any arbitrariness in the system defined by them. Here, without the justification of their superb technique, I foresaw something of the critique of Russell which was later to be carried out by Gödel and his followers, who have given real grounds for the denial of the existence of any single closed logic following in a closed and rigid way from a body of stated rules.

"To me, logic and learning and all mental activity have always been incomprehensible as a complete and closed picture and have been understandable only as a process by which man puts himself en rapport with his environment. It is the battle for learning which is significant, and not the victory. Every victory that is absolute is followed at once by the Twilight of the gods, in which the very concept of victory is dissolved in the moment of its attainment.

"We are swimming upstream against a great torrent of disorganization, which tends to reduce everything to the heat-death of equilibrium and sameness described in the second law of thermodynamics. What Maxwell, Boltzmann, and Gibbs meant by this heat-death in physics has a counterpart in the ethics of Kierkegaard, who pointed out that we live in a chaotic moral universe. In this, our main obligation is to establish arbitrary enclaves of order and system. These enclaves will not remain there indefinitely by any momentum of their own after we have once established them. Like the Red Queen, we cannot stay where we are without running as fast as we can.

"We are not figh ting for a definitive victory in the indefinite future. It is the greatest possible victory to be, to continue to be, and to have been. No defeat can deprive us of the success of having existed for some moment of time in a universe that seems indifferent to us.

"This is no defeatism, it is rather a sense of tragedy in a world in which necessity is represented by an inevitable disappearance of differentiation. The declaration of our own nature and the attempt to build up an enclave of organization in the face of nature's overwhelming tendency to disorder is an insolence against the gods and the iron necessity that they impose. Here lies tragedy, but here lies glory too.

"These were the ideas I wished to synthesize in my book on cybernetics" [177, pp. 323-325].

Wiener's entry into cybernetics did not represent any sudden shift 
on his part. I have already mentioned several times the importance of physical problems in motivating Wiener. Wiener was well aware of this and often discussed the physical origin of much of his work. However his work such as generalized harmonic analysis and of course that on Tauberian theorems, to which his harmonic analysis had led him, were so rigorously formulated as pure mathematical theories that there was some skepticism about the source of his inspiration. G. H. Hardy once asked me whether Wiener's claims about the applied origin of his work was not a "pose." In my opinion it was decidedly not a pose. In fact a perusal of $I$ am a mathematician reveals a large number of references to physicists including Gibbs, Maxwell, Planck, Einstein and Born, and to Heaviside. Wiener's comments reveal an intimate acquaintance with and a deep appreciation for their work. He also has references to a number of mathematicians but says almost nothing about what they did with the exception of Lebesgue whose work is described in almost physical terms. We saw that although he knew and admired Hardy it was Ingham who told him about the work of Hardy and Littlewood on Tauberian theorems in 1926. Indeed Wiener was largely unfamiliar with the mathematical work of some of the mathematicians he admired very much.

One of his several major aspirations incidentally was to be as important a contributor to electrical engineering as Heaviside was. I believe he succeeded in this aim. Wiener was a great admirer of Heaviside. He wrote a novel, The tempter [195]. Wiener informed me that his inspiration for the character Woodbury was Heaviside while Dominguez was suggested to him by Pupin.

Wiener's later work in mathematics was done almost entirely in collaboration with other mathematicians. Perhaps the best of this work is that which arose from the problem of extending prediction theory to several variables. In my opinion most of his work in cybernetics was not mathematical.

Through cybernetics Wiener had become widely known all over the world to people who regarded his mathematics as rather dry, narrow, incomprehensible technical work. To a considerable extent he lost contact with the younger members of the mathematical community. In the preface of his book Ex-prodigy [165] which appeared in 1952 he mentions sixteen people to whom he had submitted the manuscript for criticism. Not one of these is a mathematician. In his last years he probably knew none of the mathematicians under 35 in the Greater Boston Area with the possible exception of Rota with whom he could converse in Italian. Wiener was proficient in most of the 
languages of Western Europe and also had a limited conversational ability in Chinese. He loved to use these languages.

With the publication of his book Cybernetics [138] in 1948, Wiener had quickly become a public figure. Over the years an International Association for Cybernetics has been formed, international congresses are held, and an international journal exists. In the Soviet Union where Wiener was first accused of propounding bourgeois heresy, a later liberalization saw the formation of Institutes of Cybernetics.

It is of interest to see Wiener as he appeared to those who knew him only as the founder of cybernetics. The following excerpts are from an article by S. Toulmin, Director of the Nuffield Foundation Unit for the History of Ideas in London, which appeared as the lead article in the New York Review 3, No. 3, Sept. 24, 1964.

"He was (to use the word in an entirely innocent sense) the most peculiar American in my experience, and even in England I can liken him only to the late Sir Thomas Beecham. The similarities between the two men were no accident. True: they had a certain physical resemblance. Both of them were short, myopic, tubby. But their rotundity was more than a genetic coincidence: in both men it marked out the cosmopolitan, the bon vivant. [In fact he was a vegetarian and his moral outlook was Puritanical.] With it, there went a rotundity of expression in public conversation-I nearly said monologuewhich was too puckish to be called pompous, and an assumed air of prejudice and self-importance so extreme it became a joy to observe. For so many of the barbs in which both men indulged were penetrating and well-placed; and after all, on these occasions their tongues were never far from their cheeks ..."

"... he graduated Ph.D. from Harvard at eighteen. After seven more years of study and teaching in Europe and the U. S., he found his life's niche at the Massachusetts Institute of Technology and there he took root, gradually building up a solid though unspectacular reputation with papers on a variety of mathematical subjects-notably on Fourier integrals, about which he published a book in 1933."

"The result [of his war work] was 'cybernetics'-i.e., the general theory of control and communication-and it was in this field that Wiener was to spend the second, and more striking half of his professional career."

"If the idea of a 'thinking machine' was to escape from being a contradiction in terms, ... it was necessary to develop a systematic mathematical theory, capable of representing, without distinction, 
both the interactions of brain and limbs involved in rational behavior, and also the networks and linkages required in order to construct an artefact capable of simulating that behavior;... (After all, the power of the 'new philosophy' lay not in bare appeals to mechanical analogies, but in its method of proof by way of mathematics ....) ... the . . fundamental mathematical victory is owing above all to Norbert Wiener."

This is how Wiener's cybernetics appears to a nonmathematician, who regards cybernetics as a mathematically demonstrated theory. In fact, cybernetics is so broad that it probably cannot be viewed as a mainly mathematical theory capable of being demonstrated in the spirit of mathematics. The more sharply defined and narrower but correspondingly deeper areas associated with Automata Theory or Information Theory are certainly branches of applied mathematics, but it is not clear that cybernetics can be so classified.

Not many weeks before his death on March 18, 1964 Wiener was invited to Washington to receive from President Johnson The National Medal of Science. It was a fine culmination to a career devoted to the goal of achieving excellence in creative scientific work. Wiener was surprised when he learned that among the organizations that had proposed his name for this distinction was the American Mathematical Society. He was very impressed with the appropriateness of the citation accompanying the award and was almost unable to believe that it had been prepared from a draft submitted by a Princeton mathematician. To the end he could not realize that he was really accepted by the American mathematical community.

Massachusetts Institute of Technology 